\title{
Synthesis, Characterization and Biological Screening of Azepine Derivative: 2-hydroxy-1,3-di(naphthalene-2-yl)-1H-benzo[b]azepine-5(4H)one
}

\author{
Amit Sharma ${ }^{1}$, Ashok Kumar Singh ${ }^{* 1}$ \\ ${ }^{1}$ Department of Chemistry, Tri-Chandra Multiple Campus, Tribhuvan University, Kathmandu \\ *Corresponding E-mail: ashokksingh016@gmail.com \\ (Received: September 30, 2020; Revised: January 7, 2021; \& Accepted: January 10, 2021)
}

\begin{abstract}
The synthesis of unsaturated heterocyclic compounds containing nitrogen atoms in the ring is very important due to its various biological application in the pharmaceutical industry. Azepine derivatives find numerous application almost every field in medicinal chemistry and some of its are commercially available as drugs. The two-component of azepine derivatives were synthesized by using the aniline and maleic anhydride as a starting material followed by condensation with sodium borohydride in presence of dry benzene, subsequently cyclization by polyphosphoric acid then, finally by an addition reaction with naphthalene-2-ol to form the desired derivative. The formation of the synthesized azepine derivative was confirmed by spectral techniques such as IR, ${ }^{1} \mathrm{H}-\mathrm{NMR}$, and ${ }^{13} \mathrm{C}-\mathrm{NMR}$. The antibacterial assay shows that the synthesized compound (2A) possesses the most highly potent activity in the Bacillus subtilis and moderate activity against other different strains of bacteria and fungi.
\end{abstract}

Keywords: Azepine derivatives, heterocyclic, pharmacological, antibacterial, antifungal

\section{Introduction}

Azepine is an unsaturated heterocyclic organic compound of seven atoms, with nitrogen replacing a carbon at one position. Its chemical formula is $\mathrm{C}_{6} \mathrm{H}_{7} \mathrm{~N}$ and its molar mass is 93.13 gmol $^{-1}$ [1]. Azepine is a seven-membered nitrogen heterocycle with a biologically active epitope and a useful building block in the construction of various organic molecules. When a group or group of atoms is attached to the azepine ring, where there are profound novel influences in the biological activity of these molecules [2].

Azepine and its derivatives are imperative types of compounds that have been widely explored for the biological activities in the pharmaceutical industry. Pharmacological activities of azepine include antibacterial [3], antiviral, antioxidant, anticancer and antitumor [4,5], antiparasitic [6], antiemetic, antihistaminic, spasmolytic, antagonistic [7], anticonvulsive, anti-inflammatory, and anti-fungicidal activities [8]. These derivatives are also used in antimalarial drug therapy, anti-HIV, and other various pharmaceutical applications [9]. Even azepine based drugs are used for the treatment of Parkinson's and Alzheimer's diseases since they exhibit anticonvulsant activity and may be used as minor tranquilizers. Some azepine derivatives (Triazepine) affects the central nervous system and exhibit pesticidal and herbicidal activities $[10,11]$.

Due to the unique flexibility of the seven-membered ring, it has received much more attention in both materials and the medicinal industry. An effective anticonvulsant drug, 5H-dibenzo[b,f]azepine-5carboxamide, was the first synthesis by Schindler in 1960, and since, then it has become the most frequently prescribed the first-line drug for the treatment of epilepsy [12,13]. Because of extensive biological activities of azepine analogous, a facial synthesis of 2-hydroxy- 1,3-di(naphthalene2-yl)-1H-benzo[b]azepine-5(4H)one (2A) and 1H-dibenzo[b]azepine-2,5-dione (1A) using PPA has been undertaken and tested for antimicrobial activity against different pathogens.

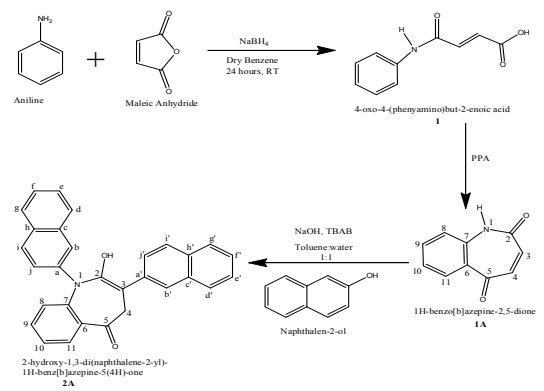

Scheme 1: Scheme for the synthesis of azepine derivatives 


\section{Materials and Methods}

A typical procedure for the synthesis of 4-oxo-4(phenylamino)but-2-enoic acid (1)

Sodium borohydride $(0.38 \mathrm{~g})$ in dry benzene $(15 \mathrm{~mL})$ was stirred for $15 \mathrm{~min}$. Then, aniline $(0.95 \mathrm{~mL})$ was added to it and stirred for an hour. The powdered maleic anhydride (1.48 g) was added to the reaction mixture and stirred for 24 hours.

The reaction mixture was diluted with an equal volume of water. The benzene layer along with precipitate was separated from the aqueous layer. The benzene layer was extracted with $5 \%$ of $\mathrm{NaHCO}_{3}$ and acidified with $2 \mathrm{~N} \mathrm{HCl}$. The precipitate was filtered and the crude solid was recrystallized from ethanol to achieve (1) as white solid [8].

\section{A typical procedure for the synthesis of 1H-dibenzo[b]azepine-2,5-dione (1A)}

The compound (1) obtained from the above procedure i.e. 4-oxo-4-(phenylamino)but-2-enoic acid (1.91 g) in PPA $(20 \mathrm{~mL})$ was refluxed for 3 hours at $80^{\circ} \mathrm{C}$ and then stirred at room temperature for 12 hours.

The reaction mixture was diluted with cold water and extracted with chloroform $(3 \times 20 \mathrm{~mL})$. The organic layer was washed with $5 \% \mathrm{NaHCO}_{3}(3 \times 20 \mathrm{~mL})$ and washed with water $(3 \times 20 \mathrm{~mL})$. The organic layer was dried over anhydrous sodium sulfate and evaporated to dryness. The crude solid was recrystallized with ethanol to achieve (1A) as a brownish white solid [8].

\section{Physical properties}

Molecular formula $=\mathrm{C}_{10} \mathrm{H}_{9} \mathrm{NO}_{2}$, Molecular mass $=175.18 \mathrm{gmol}^{-1}$, Color $=$ Brownish white, Yield $=74 \%$ Melting point $=167-169^{\circ} \mathrm{C}$

IR $v_{\max }$ (selected bands) $\mathrm{cm}^{-1}=3344(\mathrm{~s}), 3084(\mathrm{~m})$, 1675(w), 1573(m), 1379(s), and 994(s). ${ }^{1} \mathrm{H}-\mathrm{NMR}$ $\left.(500 \mathrm{MHz}, \text { DMSO-d })_{6}\right)=\delta$ ppm: 7.8614-7.7962 $(1 \mathrm{H}$, d, H-11), 7.7962-7.7679 (1H, t, H-9), 7.7763-7.6749 $(1 \mathrm{H}, \mathrm{d}, \mathrm{H}-8), 7.6074-7.5776(1 \mathrm{H}, \mathrm{d}, \mathrm{t}-10), 5.4206$ $(1 \mathrm{H}, \mathrm{H}-3)$, and $5.4206(1 \mathrm{H}, \mathrm{H}-4)$.

${ }^{13} \mathrm{C}-\mathrm{NMR}\left(125 \mathrm{MHz}, \mathrm{DMSO}-\mathrm{d}_{6}\right)=\delta \mathrm{ppm}: 170.6355$ (C-5), 147.3104 (C-2), 134.1688 (C-7), 128.9088 (C9), 128.9088 (C-11), 124.8834 (C-8), 122.9313 (C-6), 122.9313 (C-10), 69.8616 (C-3), and 69.8616 (C-4).

A typical procedure for the synthesis of 2-hydroxy1,3-di(naphthalene-2-yl)-1H-benzo[b]azepine5(4H)-one (2A)

The compound (1A) which was obtained from the above step i.e. 1H-dibenzo[b]Azepine-2,5-dione was taken in a mixture of toluene and water in the ratio of 1:1 and sodium hydroxide was added followed by the tetra-n-butylammonium bromide at room temperature. After 15 minutes, naphthalen-2-ol was added to a reaction mixture, which was heated at 60 ${ }^{\circ} \mathrm{C}$ for 5 hours. After the completion of the reaction, the reaction mixture was diluted with water $50 \mathrm{~mL}$. The aqueous layer was extracted with ethyl acetate $(3 \times 20 \mathrm{~mL})$, and the combined ethyl acetate layer was washed with $0.1 \mathrm{~N}$ hydrochloric acid $(2 \times 25 \mathrm{~mL})$. Finally, the organic layer was dried over anhydrous sodium sulfate. Then, the compound was recrystallized in ethyl acetate and hexane, to yield (2A) as a light greenish solid [14].

\section{Physical properties}

Molecular formula $=\mathrm{C}_{30} \mathrm{H}_{21} \mathrm{NO}_{2}$, Molecular mass $=$ $427.49 \mathrm{gmol}^{-1}$, Color $=$ Light greenish, Yield $=69 \%$ Melting point $=212^{\circ} \mathrm{C}$

IR $v_{\max }$ (selected bands) $\mathrm{cm}^{-1}=3479(\mathrm{w}), 3017-$ 2914(m), 1771(s), 1437(m), 1078(s), and 718(s).

${ }^{1} \mathrm{H}-\mathrm{NMR}\left(500 \mathrm{MHz}, \mathrm{DMSO}-\mathrm{d}_{6}\right)=\delta \mathrm{ppm}: 13.406(1 \mathrm{H}$, s, HO-), 8.100 (1H, H-d'), 8.093 (1H, H-g'), 8.087 (1H, H-g), $8.081(1 \mathrm{H}, \mathrm{H}-\mathrm{i}), 8.076\left(1 \mathrm{H}, \mathrm{H}-\mathrm{b}^{\prime}\right), 8.068$ $(1 \mathrm{H}, \mathrm{H}-\mathrm{d}), 8.025\left(1 \mathrm{H}, \mathrm{H}-\mathrm{i}^{\prime}\right), 8.022(1 \mathrm{H}, \mathrm{s}, \mathrm{H}-\mathrm{b}), 8.015$ (1H, H-e'), 8.009 (1H, H-f'), 8.004 (1H, d, H-11), $7.998(1 \mathrm{H}, \mathrm{H}-\mathrm{e}), 7.990(1 \mathrm{H}, \mathrm{H}-\mathrm{j}), 7.987(1 \mathrm{H}, \mathrm{H}-\mathrm{j})$, 7.853-7.778 $(1 \mathrm{H}, \mathrm{d}, \mathrm{H}-8), 7.763-7.603(1 \mathrm{H}, \mathrm{dd}, \mathrm{H}-\mathrm{f})$, 7.588-7.567 (1H, t, H-10), 7.562-7.55 (1H, dd, H-9), and 5.415 (2H, s, H-4).

${ }^{13} \mathrm{C}-\mathrm{NMR}\left(125 \mathrm{MHz}, \mathrm{DMSO}-\mathrm{d}_{6}\right)=\delta \mathrm{ppm}: 171.116$ (C-5), 168.998 (C-2), 163.720 (C-7), 163.72 (Ca), 147.787 (C-9), 136.659 (C-11), 136.659 (C-c), 136.659 (C-d), 136.659 (C-h), 136.659 (C-c'), 136.659 (C-h'), 134.654 (C-g'), 134.654 (C-i'), 131.722 (C8), 131.722 (C-i), 129.396 (C-d'), 129.396 (C-e'), 129.396 (C-f'), 125.825 (C-j'), 125.371 (C-e), 125.371 (C-f), 125.371 (C-g), 125.339 (C-6), 125.339 (C10), 123.417 (C-b), 123.41 (C-j), 123.41 (C-a'), $123.41\left(\mathrm{C}-\mathrm{b}^{\prime}\right)$, and $70.346(\mathrm{C}-3)$.

\section{Results and Discussion}

The characteristics of the two azepine derivatives, that are $1 \mathrm{H}$-dibenzo[b]azepine-2,5-dione (1A) and 2-hydroxy- 1,3-di(naphthalene-2-yl)-1H-benzo[b] azepine- $5(4 \mathrm{H})$ one $(2 \mathrm{~A})$ are examined by the various spectroscopic parameters such as Fourier-transform infrared spectroscopy and Nuclear magnetic resonance spectroscopy ( ${ }^{1} \mathrm{H}-\mathrm{NMR}$ and ${ }^{13} \mathrm{C}$-NMR). The biological activities of the compounds are also analyzed.

\section{FT-IR analysis}

The FTIR spectra of the studied compound 2A show a weak band for stretching hydroxyl group (-OH) at the range of $3479 \mathrm{~cm}^{-1}$ due to the properties that exhibit excellent hydrogen bonding and also shows a $-\mathrm{OH}$ bending vibration at $1437 \mathrm{~cm}^{-1}$. Furthermore, 
medium bands in the range of $3017-2914 \mathrm{~cm}^{-1}$ are observed for compound $2 \mathrm{~A}$ are attributed to the stretching vibration of aromatic hydrogen. However, a strong band in the region of $1771 \mathrm{~cm}^{-1}$ is observed in the spectra due to stretching vibration of the carbonyl group $(\mathrm{C}=\mathrm{O})$ and a strong band at $1078 \mathrm{~cm}^{-1}$ due to the $\mathrm{C}-\mathrm{H}$ bend vibration.

Meanwhile, the spectra of compound 1A show a sharp and strong band at $3344 \mathrm{~cm}^{-1}$ is due to the presence of stretching vibration of the N-H bond. The compound exhibit Amide I and Amide II bands at $1675 \mathrm{~cm}^{-1} 1573$ $\mathrm{cm}^{-1}$ respectively. These two bands are due to the $\mathrm{C}=\mathrm{O}$ stretching vibration and $\mathrm{N}-\mathrm{H}$ bending vibration respectively. Also, a weak band at the range of 3084 $\mathrm{cm}^{-1}$ is observed which are the bands of aromatic hydrogen.

\section{${ }^{1} \mathrm{H}-\mathrm{NMR}$ analysis}

The signal of most deshielded proton of $-\mathrm{OH}$ is observed most downfield at around 13 ppm because

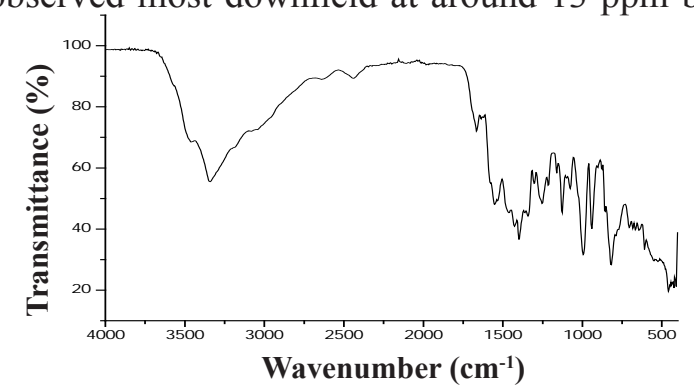

Figure 1: IR spectra of synthesized compound (1A)

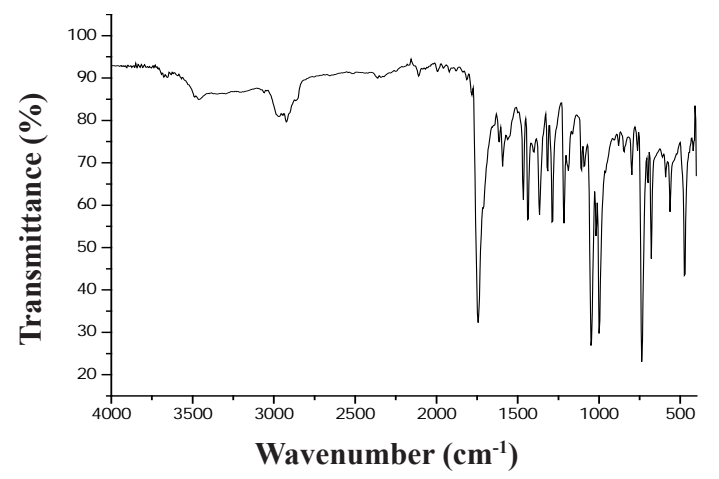

Figure 2: IR spectra of synthesized compound (2A)

this hydrogen is bonded with highly electronegative atom oxygen and $\alpha$-position is occupied by more electronegative atom nitrogen. On the other hand, the $\mathrm{H}-4$ proton is shielded and is observed upfield at around $5 \mathrm{ppm}$, it is because of the resonance effects of an oxygen atom and double bond present at the $\beta$-position of the H-4 atom and also shows an integration of two protons. The H-9 proton shows a signal at around 7.562-7.55 ppm and the H-f proton shows the signal at around 7.763-7.603, whereas both the proton shows a duplet of duplet. Similarly, the

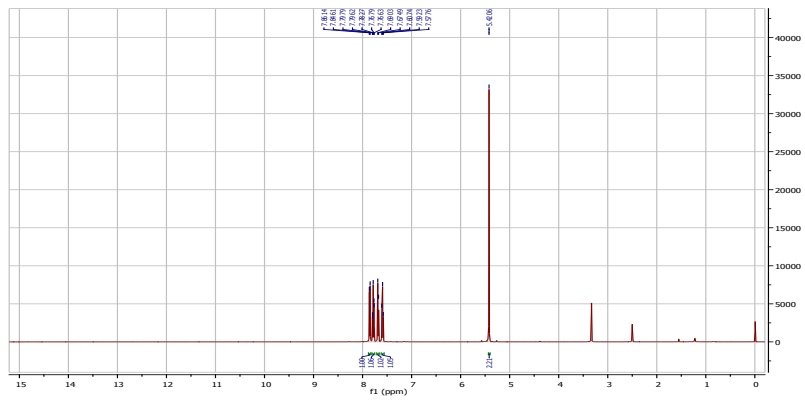

Figure 3: 1H-NMR spectra of synthesized compound (1A)

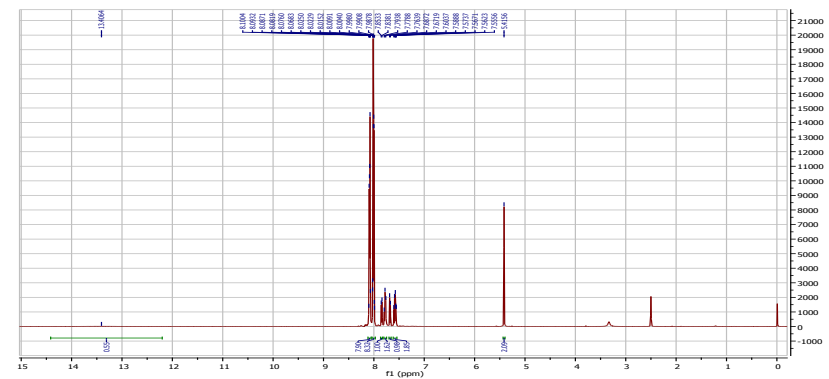

Figure 4: 1H-NMR spectra of synthesized compound (2A)

signals for all the naphthyl protons are deshielded which are observed downfield at around $7.990-8.100 \mathrm{ppm}$.

However, for compound 1A, the proton of $\mathrm{H}-3$ and $\mathrm{H}-4$ are shielded and are observed upfield at around $5.5 \mathrm{ppm}$, it is because that the proton of doublebonded carbon is a resonance with the two carbonyl group present neighbor to the double bond. Whereas the signal for aromatic proton i.e. H-8, H-9, H-10, and $\mathrm{H}-11$ appears at $7.5776-7.8614 \mathrm{ppm}$.

\section{${ }^{13} \mathrm{C}-\mathrm{NMR}$ analysis}

The signal of ${ }^{13} \mathrm{C}-\mathrm{NMR}$ depends upon the carbon atom bonded with the substitution group or atom. The signal of the C-5 position of carbon is more deshielded due to the presence of an oxygen atom. ${ }^{13} \mathrm{C}-\mathrm{NMR}$ signals of C-5 in two different compounds $1 \mathrm{~A}$ and $2 \mathrm{~A}$ appear at $170.6355 \mathrm{ppm}$ and $171.116 \mathrm{ppm}$ respectively. Similarly, the signal of the C-2 position of carbon is also deshielded due to the presence of a hydroxyl group directly attached to the C-2 Carbon and one nitrogen atom at the $\alpha$-position of the azepine ring. The ${ }^{13} \mathrm{C}-\mathrm{NMR}$ signals of $\mathrm{C}-2$ in compound $2 \mathrm{~A}$ appeared at $168.998 \mathrm{ppm}$. Likewise the ${ }^{13} \mathrm{C}-\mathrm{NMR}$ signals of C-8, C-a, and C-a' are also deshielded and appear at $163.70 \mathrm{ppm}$. It is because of the presence of nitrogen atom directly to that carbon. On the other hand, the signal for C-3 is more shielded and appears upfield with a $70.346 \mathrm{ppm}$. The signal is upfield due to the presence of double bond and electronegative nitrogen as well as hydroxyl group directly attached to the $\alpha$-position of $\mathrm{C}-3$, which undergo resonance 


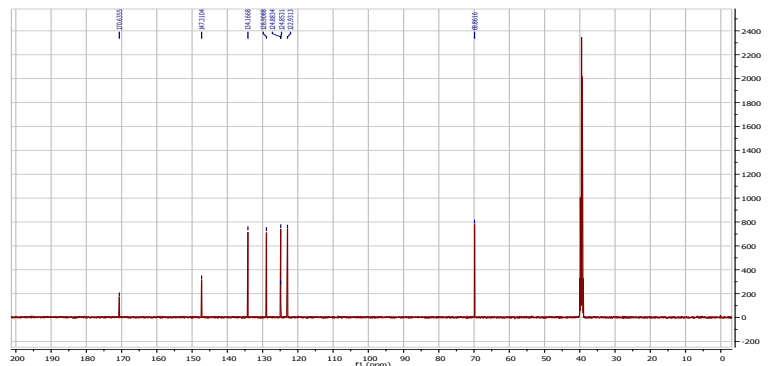

Figure 5: 13C-NMR of synthesized compound (1A)

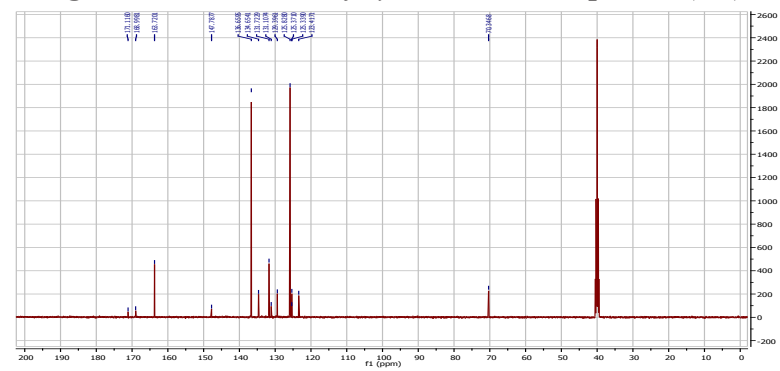

Figure 6: ${ }^{13} \mathrm{C}-N M R$ of synthesized compound (2A)

hybrid. Similarly, the signal for C-4 is overlapped with the signal of the solvent. In a compound $2 \mathrm{~A}$, the peaks for the naphthyl carbon are recorded at a range of $123.417-136.659 \mathrm{ppm}$.

Although the C-2 Carbon has directly attached more electronegative nitrogen atom and an oxygen atom, it is less deshielded than the C-5 Carbon in compound $1 \mathrm{~A}$ is due to the presence of a double bond at the $\alpha$-position of C-2 carbon which undergoes resonance with the lone pair of nitrogen electron and an oxygen atom. The signal for the $\mathrm{C}-2$ carbon atom of compound $1 \mathrm{~A}$ is recorded at $147.3104 \mathrm{ppm}$. However, the signal for C-3 carbon is observed at more shielded, with a $69.8616 \mathrm{ppm}$ due to the resonance of double bond with the lone pair of electron of two oxygen atoms. Finally, the signals for the aromatic carbon are recorded at the range of $122.9313-134.1668 \mathrm{ppm}$.

\section{Antimicrobial activity}

The antimicrobial activity of all the synthesized azepine derivatives was studied against two different bacterial strains. One gram-positive i.e Bacillus subtilis and another is gram-negative i.e Enterobacter cloaceae, using Ofloxacin as the positive control, whereas fungal strain Aspergillus spp. using methanol as the solvent control.

Table 1: Antibacterial activity of synthesized compounds

\begin{tabular}{|l|c|c|c|c|c|}
\hline \multirow{2}{*}{$\begin{array}{l}\text { Bacterial } \\
\text { Strain }\end{array}$} & \multicolumn{4}{|c|}{ The diameter of the Zone of Inhibition (mm) } \\
\cline { 2 - 6 } & \multicolumn{2}{|c|}{ Compound (1A) } & \multicolumn{2}{c|}{$\begin{array}{c}\text { Compound } \\
(2 \mathrm{~A})\end{array}$} & Ofloxacin \\
\cline { 2 - 6 } & $\begin{array}{c}1 \mathrm{mg} / \\
\mathrm{mL}\end{array}$ & $\begin{array}{c}5 \mathrm{mg} / \\
\mathrm{mL}\end{array}$ & $\begin{array}{c}1 \mathrm{mg} / \\
\mathrm{mL}\end{array}$ & $\begin{array}{c}5 \mathrm{mg} / \\
\mathrm{mL}\end{array}$ & $\begin{array}{c}0.3 \mathrm{mg} / \\
\mathrm{mL}\end{array}$ \\
\hline $\begin{array}{l}\text { Bacillus } \\
\text { subtilis }\end{array}$ & 12 & 13 & 22 & 24 & 42 \\
\hline $\begin{array}{l}\text { Enterobacter } \\
\text { cloaceae }\end{array}$ & 10 & 12 & 0 & 06 & 39 \\
\hline
\end{tabular}

Table 2: Antifungal activity of synthesized compounds

\begin{tabular}{|l|l|l|l|l|l|}
\hline \multirow{2}{*}{ Fungal strain } & \multicolumn{4}{|c|}{ The diameter of the zone of inhibition (mm) } \\
\cline { 2 - 6 } & \multicolumn{2}{|l|}{$\begin{array}{l}\text { Compound } \\
(1 \mathrm{~A})\end{array}$} & \multicolumn{2}{l}{$\begin{array}{l}\text { Compound } \\
(2 \mathrm{~A})\end{array}$} & $\begin{array}{l}\text { Control } \\
\text { (Methanol) }\end{array}$ \\
\hline \multirow{3}{*}{ Aspergillus spp. } & $400 \mu \mathrm{g}$ & $\begin{array}{l}500 \\
\mu \mathrm{g}\end{array}$ & $\begin{array}{l}400 \\
\mu \mathrm{g}\end{array}$ & $\begin{array}{c}500 \\
\mu \mathrm{g}\end{array}$ & $20 \mu \mathrm{L}$ \\
\cline { 2 - 6 } & $3 \mathrm{~mm}$ & $4 \mathrm{~mm}$ & $9 \mathrm{~mm}$ & $11 \mathrm{~mm}$ & No activity \\
\hline
\end{tabular}

\section{Antibacterial activity}

The zone of inhibition shows by the two synthesized compounds have been tabulated in table 1. The antibacterial activity of the two synthesized compounds viz. $1 \mathrm{~A}$ and $2 \mathrm{~A}$ show good activity against the Bacillus subtilis. Compound 2A was found to exhibit the most highly potent activity than the compound 1A in the Bacillus subtilis. Against Enterobacter cloaceae, compound 2A was found to be inactive at a concentration of $1 \mathrm{mg} / \mathrm{mL}$. The other compound 1A shows the moderated activity at both the concentration.

\section{Antifungal activity}

Against Aspergillus spp. the compound 1A was found to be least effective whereas compound $2 \mathrm{~A}$ exhibit moderate activity.
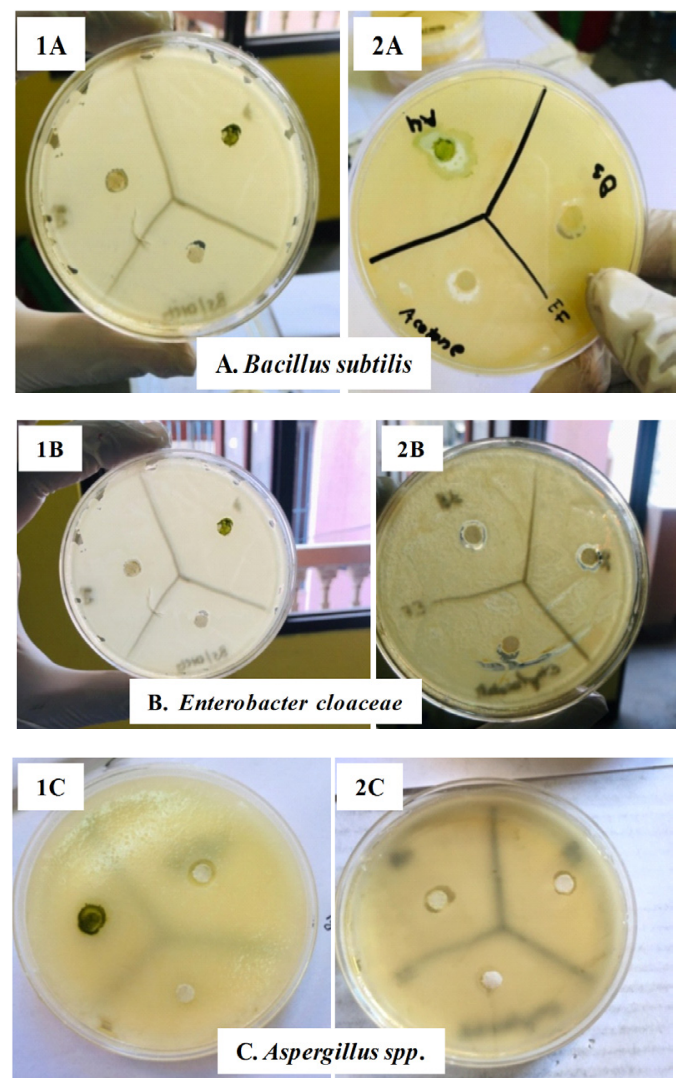

Figure 7: Antimicrobial activities of synthesized compounds against (A) Bacillus subtilis (B) Enterobacter cloacae, and (C) Aspergillus spp.

\section{Conclusion}

This study concludes that the two pieces of azepine derivatives were synthesized i.e. 
1H-dibenzo[b]azepine-2,5-dione and 2-hydroxy1,3-di(naphthalene-2-yl)-1H-benzo[b]azepine-5(4H) one. Both the compounds are synthesized from aniline and maleic anhydride as a starting material. However, a former one is a two-step process and the latter one is synthesized from a former one by addition reaction. The formation of azepine derivatives was supported by IR, ${ }^{1} \mathrm{H}-\mathrm{NMR}$, and ${ }^{13} \mathrm{C}-\mathrm{NMR}$ spectroscopy.

In the present study, it has found that compound 2A was found to be exhibit the most highly potent activity than the compound 1A in Bacillus subtilis. And, against Aspergillus spp, the compound 1A was found to be the least activity whereas compound $2 \mathrm{~A}$ exhibits moderate activity.

On the other hand, these research results have pointed out further possibilities of works on these virgin compounds creating an opportunity for scientific research to give birth to potent lead molecules as in pharmaceutical and also for the welfare of humanity.

\section{Acknowledgments}

The authors are thankful to the Department of Chemistry, Tri-Chandra Multiple Campus, Kathmandu, Nepal for providing the facilities for carrying out this research work and also Sogang University, South Korea, Seoul for continuous help.

\section{References}

1. A. A. Fesenko and A. D. Shutalev, Synthesis of nitrogen-containing heterocyclic compounds by rings enlargement reaction through bicyclic cyclopropane intermediates (Reviews), Chemistry in Heterocyclic Compounds, 2013, 49(6), 827848. (DOI: 10.1007/s10593-013-1318-x).

2. N. Bennamane, R. Kaoua, L. Hammal, and B. N. Kolli, Synthesis of new amino-1,5benzodiazepine and benzotriazole derivatives from dimedone, Organic Communications, 2008, 1(3), 62-68.

3. N. Bozinovic, I. Novakovic, S. K. Rajacic, I. M. Opesenic, and B. A. Solaja, Synthesis and antimicrobial activity of azepine and thiepine derivatives, Journal of Serbian Chemical Society, 2015, 80(7), 839-852. (DOI: 10.2298/ JSC150116013B).

4. M. P. Sadashiva, Basappa, S. N. Swammy, F. Li, K. A. Manu, M. Senottuvelan, D. S. Prasanna, N. C. Kumar, G. Sethi, K. Sugahara, and K. S. S. Rangappa, Anticancer activity of novel dibenzo[b,f]azepine tethered isoxazoline derivatives, BMC Chemical Biology, 2012, 12(5), 1-11. (DOI: 10.1186/1472-6769-12-5).

5. A. K. Singh, V. Raj, and S. Saha, Indole-fused azepines and analogs as anticancer lead molecules: Privileged finding and future directions, European
Journal of Medicinal Chemistry, 2017, 142, 244265. (DOI: 10.1016/j.ejmech.2017.07.042).

6. A. Palma, A. F. Yepes, S. M. Leal, C. A. Coronada, and P. Escobar, Synthesis and invitro activity of new tetrahydronaphtho[1,2-b] azepine derivatives against Trypanosoma cruzi and Leishmania chagasi parasites, Bioorganic \& Medicinal Chemistry Letters, 2009, 19, 23602363. (DOI: 10.1016/j.bmcl.2008.05.013).

7. C. Z. Zhu, J. J. Feng, and J. Zhang, Rhodium(I)catalyzed intermolecular aza-[4+3] cycloaddition of vinyl aziridines and dienes: Atom-economical synthesis of enantiomerically enriched functionalized azepines, Angewandte Chemie International Edition, 2016, 55, 1-6. (DOI: 10.1002/anie.201609608).

8. A. K. Singh, Synthesis and antimicrobial activity of azepine analogue of lignan, Journal of Nepal Chemical Society, 2012, 29, 44-47.

9. K. Ramesh, S. N. Murthy, and Y. V. D. Nageshwar, Novel and efficient aqueous phase synthesis of N-substituted azepine via tandem Michael addition and cyclization in the presence of $\beta$-cyclodextrin, Tetrahedron Letters, 2011, 52, 2362-2366. (DOI: 10.1016/j.tetlet.2011.02.082).

10. H. Spedding, P. Karuso, and F. Liu, Synthesis of substituted oxo-azepines by regio and diastereoselective hydroxylation, Molecules, 2017, 22, 1871. (DOI: 10.3390/ molecules22111871).

11. A. O. Kharaneko, Strategy for the synthesis of pyrazolo[5,1-d][1,2,5] triazepinones, a new heterocyclic system, Russian Journal of Organic Chemistry, 2016, 52(9), 1322-1325. (DOI: 10.1134/S1070428016090128).

12. V. L. Himes, A. D. Michell, and W. H. DE- Camp, Structure of carbamazepine: $5 \mathrm{H}$-dibenz $[\mathrm{b}, \mathrm{f}]$ azepine-5-carboxamide, Acta Crystallographica, 1981, 37, 2242-2245. (DOI: 10.1107/ S0567740881008522).

13. J. Benes, A. Parada, A. A. Figueiredo, P.C. Alves, A. P. Freitas, D. A. Learmonth, R. A. Cunha, J. Garrett, and P. S. Da-Silva, Anticonvulsant and sodium channel-blocking properties of novel 10,11-dihydro$5 \mathrm{H}$-dibenz $[\mathrm{b}, \mathrm{f}]$ azepine-5-carboxamide derivatives, Journal of Medicinal Chemistry, 1999, 42, 2582-2587. (DOI: 10.1021/jm980627g).

14. M. K. Shankar, B. C. Manjunath, K. S. V. Kumar, K. J. Pampa, M. P. Sadashiva, and N. K. Lokanath, Crystal structure, spectral studies, and hirschfeld surface analysis of 5-methyl-5H-dibenzo[b,f] azepine and 5-(4-methylbenzyl)-5H-dibenzo[b,f] azepine, Journal of Crystallography, 2014, 6, 1-9. (DOI: 10.1155/2014/862067). 